\title{
The Implementation of Mini-Enterprise Business Process Management
}

\author{
${ }^{1}$ Long Wang, ${ }^{1}$ Weining Liu, ${ }^{2}$ Zhe Wang \\ ${ }^{1}$ Shanghai University of Political Science and Law, China \\ ${ }^{2}$ Edinburgh Napier University, United Kingdom
}

\begin{abstract}
Obviously, It is important for the mini-enterprise to acknowledgement that how to win the customers and markets, because the products must be continuously evolved so as to satisfy the customer, otherwise it will be disused by the market, that is a major problems for nowadays mini-enterprise business process management. In fact, in order to satisfy the customers, the overall business processes for minienterprises are mostly based on integrated business process, optimization on the integrated business process is vital for a successful min-enterprise. this paper explores how to optimize the business process of mini-enterprises based on the general principle of enterprise business process management and the main feature of the mini-enterprise, so as to instruct the mini-enterprise to control, enhance and optimize the business process in order to meet the inner requirements from the development of the enterprise and adapt itself with the continuous changes of the outside environment, most vitally it can enhance the process or re-design the process so as to meet business demands from customers
\end{abstract}

\section{Introduction}

Process optimization as a term of business management discipline, has receives huge amounts of attention these years, major enterprises in European and American have began to use new optimized management methods, the core part of these methods is process optimization, the business process management is original from the process refectory proposed by Hanmo and Qianpi, they all advocate that the process should be deeply re-designed, in order to enhance the running efficiency of the organization, business process optimization methods merge various types of process management methods, and provide the enterprise with " the most appropriate choose opportunity for business process optimization" , and it can also make up the defects of other management methods.[1][2][3] The process management will not only focus on the enterprise inner resource management and competition ability enhancement, but also focus on the enterprise outside resource management and competition ability enhancement, this can be realized based on resources further integration to enhance the competition ability; the enterprise in our country, especially the traditional mini-enterprise management system 'running pattern is different from the current developed new management pattern, it cannot be adapted with the modern days process management requirements, that will affects the survival and competition ability of our country's enterprise, so that the research on the process management optimization principles has dominate theory and practical value to optimize our country's mini-enterprise business process management.

\section{Related Theory}

The process management theory is first be proposed by European and American companies, and it has been studied in the most advanced time, so that it produced many valuable theories about process management, which can benefit the research of process management. Among these theories, the most prominent one emphasis the importance of enhancing the re-design of the business process which is the fundamentally re-factory theory, the business process reconstruction theory and Sun's Theory.

\subsection{Fundamentally Re-factory Theory}

From the 80 s of last 20s century, the information technology revolution has provided comprehensive changes on the enterprise running pattern and working manner, the knowledge economics plays the critical role in various production factors, at the meantime, the traditional enterprise has to face the changing of the competition markets, and the new development of the management mechanisms based on new management theories, which makes the defects of the traditional enterprise management appearance more than before, that accelerate and stimulate the American enterprises to be more appetite on the new coming theory for 
innovative management, the fundamentally re-factory theory was proposed under such background.

What is the enterprise re-factory? Hamo's defined is: re-factory the enterprise business process thoroughly, the ultimately aim is to develop the theory in a suitable cost, high quality, aggreable service and sustainable speed, which makes the enterprise can adapt itself with customer, and change in the largest range of the modern enterprise running environment, this new definition include four fundamental elements, (1) the objects for re-constructing the enterpriseprocess (2) the object for re-constructing and organizing the enterprise - information system; (3) the aim of the enterprise reconstruction to enhance the enterprise achievement; (4) the routes of enterprise thoroughly reform

Although, the enterprise business process is start at the point of reconstructing, driven by design and integration, but its work does not stop at this stage, the business work flow will plays critical impacts on the every part of the enterprise, "enterprise re-factory "can change the existing business work flow, these changes can be summarized as the following points: 1) the initial working unit is changed to process working units. 2) the process working units itself is changed from single to multiply, 3) the employee's role is changed from under control to authorized control, 4) the training for the employee is changed from temporal training to sustainable training, 5) the judge of the achievements and paying is changed from daily payment to ultimate income, 6) the employees' value is changed from self-efficiency to the pursue of production efficiency, 7) the role of manager is changed from supervisor to trainer, 8) the organization hierarchy is changed from multiply to single, 9) the role of senior manager was changed from worker to leader.

\subsection{Theory of Business Process Reconstruction}

Huangaizhou and Meichaozu proposed a new process management in the book "exceed business process reconstruction - the research on the process management". It defines the process management as follows: it is a unified business process and it is a systematic approach to continuously enhance the achievement of the organization. this will thoroughly, fundamentally integrate the initial process management as a standardized, systematic plan.it point out that there is no need to do thoroughly amends on the whole process but only need to do a partial amends which makes the current process to be a standardized process, it also point out that, the process management is a systematical methodology and it always rise continuously as enhanced methods, which makes it has more practical meaning [6].

\subsection{Sun's Theory}

Sunshusheng think that the modern business process management not only occurs conflicts with the traditionally category on working, but also provide a way of integrating collaborations between various workings, the traditional enterprise organization more emphasis on labor based category, which makes the collaboration between different departments is very difficult, result in the low efficiency, high cost that prohibits the development of the enterprise. Now days, the process oriented enterprise organization can benefit both working and collaboration, because it is oriented to customers, and it services object is more clear, which makes enterprises and employees are more integrated [7].

\section{Analysis on Our Country's Mini- Enterprise Business Process Management}

\subsection{Inner Barriers Block the Effective Implementation of Process Management}

With the growing up of the mini-enterprise, the business activities are continuously increasing, the classifications and interactions between these business activities often cause unidentified risks, which results in the changing of the inner structures of the minienterprise, specific business activities departments are founded for particular tasks and schedule formal regulations, so that the business activities of each department can be clearly classified into several types, each types of departments focus particular one type of business activity, but such managements methods can enlarge the conflictions between each departments, the overall interest is being ignored under such conflictions

\subsection{Business Process Exists Because of Customers}

The aim of business process is to provide better, effective service for customers. We always declare that the starting point of business process for customers, the terminal of the business process is also for customers, but in the real situations, we even don't know who are our customers because of the barriers between each department. In order to service customers as maximum, principles as below should be followed.

- Construction the concept that customers are the center of the business process

- Clear that who is serviced by the business process, and what's the aim of the business process

- Always judge from of view of customers when emergent situations occur. 
- Focus on the outcomes, the achievements aim should be decided based on the outcome of business process.

- Make all the people involves in the process should have the same aims, and to achieve agreements for customers and outcomes.

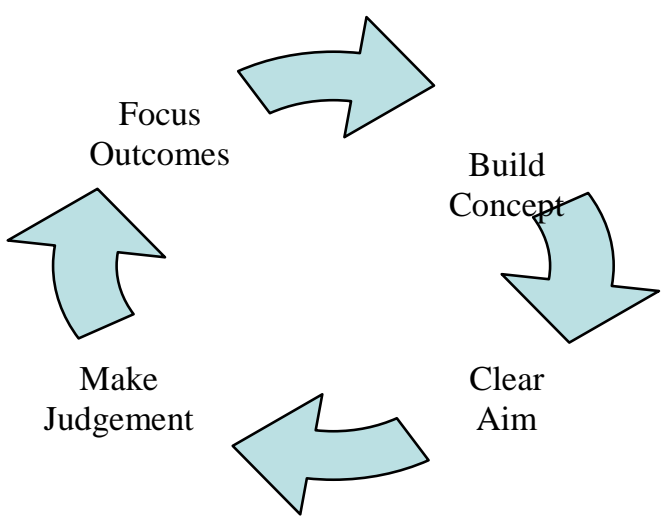

Figure 1. A simple Mini-Enterprise Business Process Management Cycle

\section{Innovative Methods for Optimizing the Business Process Management}

\subsection{The Structure Reform Based on Process}

Most of the mini-enterprises in our country are family based enterprises, most mini-enterprises have limited interactions with each other, and the interaction efficiency is quite low, most minienterprises lack of scientific methods to support in management. It is working process has limited operability and the collaboration between employees are also limited. So that, in order to solve these problems. It should begin to reform the process management. Making the enterprise change from function driven to process driven is one of the effective methods. Using the process to break the wall between each department in order to enhance the enterprise efficiency by using the information, products, and finance driven by the process. the process can be detailed on describing each part of the department and position that will clarified the responsibility of each department and make each department undertaken its duty and tasks, which can effectively push the enterprise developing forward.

\subsection{Design the Process Structure Based on its Own Feature}

In the enterprise process re-factory, it must started from analyzing the strategy of the enterprise, refine the core ability requirement of the enterprise, and corelated the processes with other processes, continuously optimize the co-related process and refine the business models, repeatedly the process until form the core competition ability of the enterprise, the process design based on such procedure will conform to its own features, culture, which can benefit the enterprise in long term for survival and grown up, this process provides more quality , usable process in the future optimization process, and such evolution can happen timely.

\subsection{The Information Infrastructure Construction Based on Business
Process}

Based on the analysis of each process, we can found the process and activities of the steps to realize the information system, and well understand which part should be supervised, and then the data analysis requirements can be proposed at the right place. It also indicates which department should be collaborated working with each other. Then the collaboration requirement should be proposed right here. And which service or business activities should be continuously evolving, then the service should not be suspended. at the meantime, the corresponded information constructions should make the decision aware the changes of the environments, in order to provide new process design and enhancement, which can avoid the un-changeable business process management that cause the low efficiency for the enterprise.

\section{Some of Related Disciplines}

With above related disciplines, we can conclude these following fundamental disciplines:

\section{Disciple for the Purpose of Customers' Benefit}

Obviously, the most important concept for business process management is the purchase of the purpose of customers' benefits. In now day's world economics environments, it has been changed from sellers' market to customers' market; the feature of the marketing is the customers' benefits decided the enterprises' developing. The customers should agree the products of the enterprise, which are the critical factors for the enterprise. If the enterprise willing to change the attitude of service providing to customers as the center of its strategy, then the design of the business process should fully be considerate under such circumstance.

\subsection{Disciple of the Equivalent Authority between Colleagues}

The implementation of the business process management must be happened based on the equivalent authority between colleagues; the concept of classes should be broken up. The manager should be aware that the irresponsible of colleagues is because you haven't shifted the responsibility to your colleagues. The role difference is only in the variance 
of the works it undertaken; there is no difference in capability and status. As a employee, it should enhance its conscience of personal right and duty, enhance it confidence and responsibility, it should has courage to hold the above things. There is a hypothesis in the design of the business process, which is the assurance of all employees involved in the business process are all qualified employees. As the manager, it should also confirm that all the employees in the enterprise are all reliable and trustworthy, only that, the employees can provide benefits and achievements for the enterprise.

\subsection{Disciple of Sharing Responsibilities}

First of all, the implementation of managing on the business process should be cleared on the responsibility and duty of each roles and positions in the enterprise. Each individual in the business process team should share the responsibility of the achievement on the business goals, which is the discipline that must be hold. Secondly, it is absolutely not sharing the same responsibility between each individual and variance based on each individual's duty in achieving the business goal based on the business process, those who main body of the team should take the major responsibility of the team work, while other should take the subsequent responsibility of the team work. The achieving of the customers' demands and growing of business profits can only be happened under the way of "putting the strength to the same direction".

\subsection{Disciple of Unified Tools}

Under normal situation's, the implementation of process management should be rely on the business process design software, and the unified analysis tools. In order to be fast in communication, convenient in interaction, the enterprise must create unified process design charts and make rules on the design of these charts including, the rules of using tables, formats, symbols and terms, etc. The enterprise should make sure that there is seamless interactions with the relevant software tools that already been used.

\section{The Discussion on the Mini-Enterprise Business Process Implementation}

Explore the main part of the mini-enterprise business process re-design

\subsection{Solving the un-Reasonable Problems during the Enterprise Decision Making}

Most of the enterprises are sponsored individually, as actually the control authority are hold by enterprise owner and its family. Its family authorizes the decision-making strictly; the manager of the enterprise can hardly make any decision, nerveless those who have been well educated in enterprise management. Most of those enterprise owners are low in academic an achievement, which limits its knowledge confident in enterprise strategy management, nerveless in technique and system innovation. The decisionmaking for the enterprise in making marketing strategy, product strategy and investment strategy are lack in reasonable agreements and innovative developments conscience, question is how to solve such critical problems?

\subsection{Solve the Problems of System Inefficiency}

The system of management is the main factors for affecting the enterprise achievements and enterprise profits. Because of lacking in professional manager, the mini-enterprises are disadvantage in talents, marketing, finance and enterprise strategy; the management of the mini-enterprise is under unformulated process, which makes the decisions making in the enterprise are under the elective model. Most owners of the mini-enterprise can not be equivalent in interacting with middle class managers and employees; question is how to solve those problems?

\subsection{Solving the Problems of System Defects}

The defects of the mini-enterprise is started when the mini-enterprise has becomes more and more complex and expanded, which is the most dangerous time of the mini-enterprise life cycle. With the expanding of the mini-enterprise, its need to import more and more professionals into the decision making layer of the mini-enterprise, which this will cause the conflicts between the professional managers and enterprise owners family's, two profits groups are created under such situations, which makes the management systems has low executing efficiency. Most of the talents will feel not valuable to continuously stay in the enterprise and at the mean time the mini-enterprise feel also hard to provide sustainable development for these talents and its own future. So that, in the enterprise human resources management, it must considerate the profits confliction between each profit groups, and optimize these conflicts in order to maximally use various wisdom and talents in the mini-enterprise.

\section{Advice and Thinking}

\subsection{Reform on the Ideals}

The management on the mini-enterprise should be correctly understood based on its necessary and importance, especially the manager of the minienterprise. Based on the feature of the mini-enterprise, 
it should be more focus on "the re-design of the business process"

So that, it is very important for the mini-enterprise manager know that the business process re-design is not the automatic of the design management, neither the quality management of the mini-enterprise, and it is totally not to lay off the employees, but it is the process of refine the management from extensive cultivations to a refinement management. It aims at reduce the process cycle, cost and unified the functions of the process so as to enhance the quality of the enterprise running. Making a solid management process, realizing the reasonable business process management, so as to optimize the enterprise process, enhances the enterprise running efficiency, making the enterprise management in a standard and formalized manner. The difficulty in this process is it refers to the inner and outside technique and social factors of the mini-enterprise.

For the mini-enterprise, it should more focus on the tight cooperation between process re-organization and enterprise strategy. The comprehensive re-design should be made on the business process, which is strategy oriented and has more additional values; it is an organic and integrative work, not a one-step thing. The strategy of mini-enterprise decides the business process management of the mini-enterprise, and the business process should sustain the enterprise strategy in real activity, the goal of the strategy must be realized on the business process. So that, the business process must be re-design based on such motivation so as to optimize and enhance the competition ability of the mini-enterprise.

\subsection{Based on the Overall Involvement and Thinking of Employees}

The overall employees of the mini-enterprise should be involved into the "business process redesign process", and it should also focus on; 1) these employees are organized as a team and the enterprise should support the team with adequate resources and power. 2) These employees should not be constrained by the higher leaders 3 ) these employees should be involved into the core process of the business, which is the decision making. 4) the involves of these employees are over all processes, which means they will not only involves into the enterprise business process design but also fully involves into the implementation.

\subsection{Main Orientation of the re-Design of the Business Process}

These business process re-design will not only needs a prospective thinking but also needs a wide spectrum, the feature of mini-enterprise is some of the business process are cross departments, when it across these departments, some of the factors may delay and reduce the efficiency of the business process, in that situation, the probability of overcome the difficulty based on such business process will be very low. So that, the re-design of the business process will not only needs prospective thinking but also needs a wide spectrum in order to avoid the lead of compensation.

\subsection{The Expenditure for the re-Design of the Business Process}

The enterprise should confirm the investment on the expenditure of the re-design process, because for the mini-enterprise it is not a low cost. During the process of re-design and re-organization, it must make sure that the investment on people; property and equipment should be adequate and appropriate. For example, under such globalization circumstance, the investment on enterprise information system reconstruction and development should be push forward based on the collaboration of chief manager of each department, including the executors, for only those people knows the problems of the e-business system.

\subsection{The Necessary of Using the Third Party Consultant}

It should maximum use the service provide by third party consultant agents, because the minienterprise are lack in the knowledge of business process re-design and re-organization, it should ask these third part consultant for help in order to achieve the success of its business goal under the lowest cost and highest efficiency.

\section{Conclusion}

Business process is the original of the advantage of mini-Enterprise Competitions

A successful mini-enterprise can not rely on excellent ideas occasionally occurs, such competitions will not guarantee the long term success of a minienterprise, all of the success must be based on a standardized business process management as shows following:

1. Design unique business activates and patterns for servicing the strategy of the Mini-enterprise

2. Accumulating and inheriting the experience and knowledge

3. Formal the very best practice of mini-enterprise and continuously promote.

4. Reduce the running cost and enhance the competition price.

The implementation of the business process management should be effective

The implementation of the business process management should be considerate based on the following criteria: 
1. The higher-level leader should promise the commitment.

2. Enhancing the quality of Service provide to customers as the ultimate aim.

3. Holding a overall comprehensive strategy for business, the strategy can reflect the interactions between strategy, people, process and technology.

4. Explore the business perspective and extend it to customers and supplying, building cooperation relations between each profits related stakeholder.

5. Encourage all the employees to engage into the business process and maximum the utility of their idea resources, encourage employees commit for achievements.

6. Focus on thinking on the outcomes.

\section{References}

[1] Jianhua Wang, Business Process ReconstructionMiddle Enterprise Running Management Pattern , A New Discussion[J] , Modernize Business Market(358)

[2] Jinghu Wang, Longbing Deng, the Business Process Management Theory in the Applying Background of our Country and its Problems.[J] Petroleum University Post,2011,(6)

[3] Shaohua He, the Business Process Management and Research in Middle Enterprise, Beijing: the Journal of enterprise Management , 2007

[4] Yurong Wang, Peng hui , Process Management[M], Beijing, Beijing University Press, 2008.

[5] ZhangBiao, Mike, hamo. the Enterprise Reconstruction in China]M]. Shenyang: NorthEast University Press, 2010

[6] JingZhong Guo, Feili, the Original of the Business Process Reconstruction, and its Evolution and Trends[J]. Modern Management. 2007(11)

[7] Junting Meng, the Research on the Business Process Reconstruction for the Middle Enterprise on its Finance Information System.[j], CHINA MANAGEMENT INFORMATIONIZATION. ChangChun, Science and Technology Press, Jiling, 2009

[8] Wei Wu, the Detailed, Quantitive Principle Introduced into Middle Enterprise for Our Country, [J] NEIMONGGU University Press, 2010,(1).

[9] Nancy Faget. Knowledge Management and the Role of the Chief Knowledge Officer[J], 2004.1. 